Article

\title{
Core Elements for Organizational Sustainability in Global Markets: Korean Public Relations Practitioners' Perceptions of Their Job Roles
}

\author{
JiYeon Jeong ${ }^{1}$ and Nohil Park ${ }^{2, *}$ \\ 1 School of Advertising \& Public Relations, Hongik University, 2639 Sejong-ro, Jochiwon-eup, Sejong 30100, \\ Korea; jyjeong@hongik.ac.kr \\ 2 Department of Health \& Strategic Communication, College of Integrated Social Science, CHA University, \\ 120 Haeryong-ro, Pocheon-si, Gyeonggi-do 11160, Korea \\ * Correspondence: no1park@cha.ac.kr
}

Received: 31 July 2017; Accepted: 10 September 2017; Published: 15 September 2017

\begin{abstract}
For the purpose of enhancing organizational sustainability in global markets, organizational public relations practitioners in international firms take roles to respond toward the global public. This study explores practitioners' perceptions of their job roles in global public relations firms and identifies the elements that support those roles. To address these concerns, a qualitative method, specifically an in-depth interview, was conducted because it endeavors to reveal and understand what lies deep within the complexity of a little-known phenomenon. As the specific public of this research, Korean practitioners were selected, since the public relations industry in Korea has been influenced by globalization, and diverse global public relations firms have branches in Korea. Analysis of in-depth interviews suggests a typology of three newly defined roles for Korean practitioners: strategic counselor/manager role, non-strategic technician role, and business manager role for practitioners' own firms. It also identifies nine elements affecting public relations practitioners' roles. The important and powerful elements were chiefly attributed to culturally specific influences. This study provides critical clues for enhancing both entrepreneurial sustainability in global markets and the professionalism of public relations. Finally, public relations practitioners will be better able to make optimal decisions regarding their client organizations' adopted strategy.
\end{abstract}

Keywords: organizational sustainability in global markets; global firms; Korea; culture; job roles; public relations

\section{Introduction}

In order to enhance organizational sustainability, the organization takes the position in decision-making, in particular, organizational public relations practitioners take roles to respond toward its public. There has been much discussion of the roles that public relations practitioners play in organizations (e.g., [1-8]). The research into practitioner role enactment is recognized as one of the main areas of theory development within public relations. Generally, these studies of public relations practitioner roles have been interested in exploring managerial roles with a particular focus on professionalism. Despite considerable research on public relations practitioners' roles, several questions remain. Most studies focus on general corporate in-house environments without looking at other public relations practitioners' work environments; for example, they do not consider whether practitioners work in corporations' in-house public relations departments or in separate public relations firms, and whether they work in domestic or global public relations firms. Does this mean that those studies assume practitioners' roles are similar in every organizational structure and culture? Prior research has also generally failed to address what processes or elements help form the roles of public relations 
practitioners. Moreover, abundant studies on practitioners' roles have developed in America, and American practitioners' role enactment has influenced public relations practice in other countries [9]. Although several studies have explored practitioners' roles in various countries and regions including South Africa [10], Singapore [11], and Latin America [12], including Chile [9], Brazil [13], and Costa Rica [14], there has been little research on Korean practitioners' perceptions of their job roles.

Therefore, the purpose of this stusdy is to examine how Korean public relations practitioners in global public relations firms perceive their roles and identify elements that support those job roles. As the focus of this research, the sample represents practitioners who work in Korean branches of global public relations firms. The public relations industry in Korea has, in recent years, developed rapidly and has been influenced by globalization, and diverse global public relations firms have branches in Korea. From the public relations perspective, this study takes a much wider conception of sustainability which implies survival and endurance through a symbiotic relationship with the environment, society, and the economy [15]. It also deals with environmental impacts triggered by corporate activities. This study provides meaningful insights into public relations professionalism as well as entrepreneurial sustainability in global markets, and contributes to the application of these results at a practical level.

\section{Literature Review}

\subsection{Job Roles of Public Relations Practitioners}

Job roles are sets of behaviors intended to deal with recurring situations in practitioners' work and to accommodate others' expectations of how their jobs should be done [16]. Roles research in public relations has tended to focus on exploring and classifying roles in typologies, as exemplified by Broom and Smith [1] and Dozier [4]. Broom and Smith's [1] four dominant theoretical practitioner roles-communication technician, expert prescriber, communication facilitator, and problem-solving process facilitator-have served as the basis for many subsequent studies of practitioner role enactment in organizations. Cutlip and his colleagues [16] mentioned that these "four major public relations roles describe much of the practice". Dozier's [4] manager-technician role dichotomy has also been widely utilized as a framework in roles research (e.g., $[5,6,17,18])$ even though some researchers have found it to be oversimplified [19-21]. Whereas the manager role is viewed as central to organizational decisions and their relative success or failure, the technician role is characterized as secondary in that decision-making opportunities are precluded. Dozier and Broom [5] note that the roles of technician and manager represent different broad sets of activities most commonly performed by practitioners in organizations. However, they acknowledged that, in actuality, "all practitioners enact elements of both managerial and technical roles, which themselves are simply useful abstractions for studying the wide range of activities that practitioners perform in their daily lives" [5] (p. 20, emphasis added). Other than the roles cited above, Toth, Serini, Wright, and Emig [22] identified an "agency profile" among a national sample of PRSA (Public Relations Society of America) members. This agency role includes the tasks of counseling, research, programming decisions, communicating with clients and coworkers, and handling correspondence with the media.

Some roles research has focused on the significance of gender (e.g., [22-31]), emphasizing both the tendency for women to be relegated to technical roles as well as the barriers they have faced in assuming more prominent managerial roles in public relations. A disparity between male and female practitioners in terms of salary and status has also been revealed. Further, the research team of DeSanto, Moss, and Newman [2,3] focused on managerial work in public relations. They found that there are a number of common elements in the pattern of "managerial" work performed by UK and US-based practitioners. They demonstrated five core areas of practitioner work: monitor and evaluator, key policy and strategy advisor, trouble shooter/problem solver, issue management expert as a managerial responsibility, and a further technical dimension labeled communication technician. 


\subsection{Job Roles of Public Relations Practitioners in Korea}

While little research has examined the roles of public relations practitioners in global public relations firms, there has been research regarding practitioners' job roles in Korea. Han's [32] study is the first to regard the typological perceptions of Korean public relations practitioners toward their job roles. Through $\mathrm{Q}$ methodology, he discerned four types: all-mighty public relations practitioner, practical public relations manager, the idealist, and the traditional public relations loyalist. The results indicate that Korean practitioners take great pride in and have optimistic perspectives of their jobs and roles both within their organizations and in society.

However, a Korean business person is likely to believe that public relations has been functioning as a publicity/public information model of public relations or as a part of advertising and marketing [33]. In fact, public relations agencies in Korea typically offer expertise in dealing with the media, even though there has been rapid development in the public relations field. The Korean Businessman's Association published "Guidelines for public relations practitioners: How business people can handle mass media" to lead practitioners toward better performance in public relations [34]. Notably, these guidelines do not focus on practitioners' professional standards but merely on techniques for media relations, or press agentry.

Kim and Hon [35] found that Korean practitioners of highly professionally-oriented public relations firms are more satisfied with their jobs than are practitioners of less professionally-oriented public relations firms. They reported that Korean practitioners have aspired to practice two-way communication or professional public relations models. Finally they concluded that, for the development of public relations in Korea, more professional public relations should be practiced, and professional strategies and skills should be advanced. However, prior research does not explain what public relations practitioners really do and what elements affect their job roles.

\section{Research Questions}

This study focuses on two research questions:

Research Question 1: How do public relations practitioners in global public relations firms in Korea understand their job roles?

This question is based on the notion that there is a role typology of Korean public relations practitioners in global companies and those role types are both empirically and conceptually distinct. Based on Cutlip and his colleagues' [16] definition of job roles-patterns of behavior to deal with recurring situations in their work and to accommodate others' expectations of what they should do in their jobs-the researchers assume that there would be a new or modified role typology with the new noticeable development of the public relations industry in Korea.

Research Question 2: What elements do public relations practitioners in global public relations firms in Korea think affect their job roles?

This is an exploratory question since there is little in the literature to suggest which particular elements affect public relations practitioners' job roles, and the operation and influence of these elements is unclear. This question is based on the assumption that cultural characteristics contribute to practitioners' job roles in global companies. Through this research question, the researchers expect to identify new elements contributing to job roles. These would constitute important research topics.

\section{Method}

A qualitative method, specifically an in-depth interview, was used for this study because it endeavors to reveal and understand what lies deep within the complexity of a little-known phenomenon [36]. This research is an independent study of previous empirical observation to identify how Korean public relations practitioners in global public relations firms perceive their roles, and there has not been a clear delineation of the elements that affect Korean public relations practitioners' 
perceptions of their job roles. The research method, with the application of appropriate methodology and resources, could yield far more impressive results than are evident at present. Thus, to answer the research questions in the most appropriate way, this research used in-depth interviews. This approach broadens the description of public relations practitioners' perceptions and discovers critical elements. They also drive the research in new directions by encouraging the exploration of additional valuable new findings which were not expected or not included in the research.

\subsection{Participants}

The interview sample was comprised of 20 public relations practitioners who work at Korean branches of five different global public relations firms. These firms are affiliated with overseas headquarters and are affected by the headquarters' rules or principles. They are also all members of the Korean PR Consultancy Association [37], Korea's largest organization for public relations firms and professionals. The interviewees covered a wide range of personal and professional backgrounds; job titles, levels of experience, age, gender, and academic degrees were considered in addressing the research topic. Prior research has shown that these characteristics are associated with public relations practitioners' roles $[17,22-31,35,38]$. The researchers approached individuals from these personal and professional backgrounds to analyze individual perceptions and to capture patterns that emerge across interviewees. This information also supports comparisons between the results of this research and those of previous contributions to the literature. The names of both participants and their places of employment have been withheld, as the interviewees were promised anonymity in the reporting of the study's results.

\subsection{In-Depth Interview Procedures}

The first interview step was "cold" e-mails sent either to the heads of the Korean branches or to the firms' contact e-mail addresses, requesting interview sessions with public relations practitioners in their own organizations. Later, the researchers contacted public relations practitioners who indicated their willingness to participate by phone or e-mail to initially discuss the interview, obtain their consent to participate, and set a time for the actual interview. In-depth interviews and follow-up interviews required the use of a computer video system and telephone, as this is an overseas study. The interviews were conducted using semi-structured and open-ended interview questions which do not limit interviewees' responses and which find comprehensive, detailed indications of what individuals feel and think about their world in reference to research questions. Since this study considers features unique to Korea, the detailed questionnaire reflects these features in the conduct of interviews. Before undertaking the interview process itself, the researchers pre-tested their interview questions, style, and technique with several Korean individuals unaffiliated with the organizations in this study. The actual queries are presented in Appendix A of this research. The interviews were conducted in an inductive and informal rather than structured manner, allowing informants to introduce topics as they saw fit. Each interview was conducted in the interviewees' native Korean during a 10-week period and ranged from one hour to three hours in duration.

\subsection{Data Analysis Technique}

To analyze broad, in-depth data, a systematic analysis plan was employed. The interview data were transcribed, checked for accuracy, grouped, and analyzed thematically after completion of all the interviews. This approach is an efficient way to review each transcript and compare it with others on a continuous basis [39]. All interview transcripts were reviewed several times until likely units of analysis could be identified, and then coded into meaningful themes involved with and relevant to the research topic. The researchers then looked for patterns among themes. To compare this research's themes and results with previous research relevant to the topic, cross-case analysis was employed to include both case-oriented analysis and a variable-oriented approach. This mixed strategy would help not only in analyzing individual perceptions, but also in capturing patterns [40] that emerge 
across interviewees. The researchers used a narrative approach in reporting the findings, since the interviewees' narratives or specific examples related to the topics which they present would be helpful to identify themes or critical findings of the study.

\section{Findings}

\subsection{Korean Public Relations Practitioners' Perceptions of Their Job Roles}

This study rediscovered three job roles among public relations practitioners in global public relations firms in Korea: strategic counselor/manager, non-strategic technician, and business manager for a practitioner's own firm. Among them, strategic counselor/manager and non-strategic technician roles basically follow concepts which were previously discussed by many scholars. However, the role types found in this study are both empirically and conceptually distinct and are newly defined and conceptualized as a typology.

\subsubsection{Strategic Counselor/Manager Role}

This study suggests that the strategic counselor/manager role that emerged in this study differs from the definition of the manager role of practitioners in previous studies because the strategic counselor/manager role here includes every function for their clients related to public relations strategies. Even press release writing and editing, and media contacts, which were categorized as elements of the technician role in prior research $[4,16]$, have been re-identified as part of a strategic counselor/manager role in this study since strategies and planning are involved with such work. This role is considered the practitioners' traditional but essential work. Specifically, this research suggests the strategic counselor/manager role can be defined as involving research, strategic and creative thinking, objective setting, programming, budgeting, and handling/counseling clients regarding issues of communication strategy, and influencing the decision-making of clients. Accountability for a program's success or failure, influencing public perceptions, and maintaining contact with headquarters would all be included in this role and are all concerned with long-term relationships. One of the significant characteristics of this typology is that it includes a media management role. Managing media is not merely related to media contact but to all activities directed at building beneficial relationships with media. An interesting finding of this study regarding managing media was that Korean practitioners commonly achieve it through building individual and personal relationships. This demonstrates how uniquely Korean cultural characteristics influence relationship-building. It also seems to demonstrate that Korean public relations practitioners' roles are still focused on publicity and are dependent on media relationships.

\subsubsection{Non-Strategic Technician Role}

A non-strategic technician role that emerged in this study encompasses roles which do not involve any strategic work. Such work could be performed by other non-practitioner employees. This role involved everyday work which is requested or decided upon, and can be substituted by others. Here, the non-strategic technician role is defined literally as an "agent role" or "servant-like assistant role". It includes media clipping, filing, delivering media monthly books, and completing invoices.

\subsubsection{Business Manager Role for Practitioners' Own Firms}

The business manager role of practitioners constitutes a new type of Korean practitioners' roles that emerged in this study. The roles can be conceptualized as one of the primary and unique roles public relations practitioners may serve in global public relations firms in order to manage their own business, a role not found in corporate in-house environments. This role is completely new, not mentioned in previous studies. This could be because practitioners who work in public relations firms compete with other firms' practitioners to gain new clients as an outside counseling firm that serves clients with one or more public relations professionals. Such a role includes cultivating new clients, 
handling new business pitches including developing proposals, designing client contracts, managing clients, and managing the firms' employees.

\subsubsection{The Relationship between Practitioners' Backgrounds and Perceptions of Roles}

Korean public relations practitioners perceive that their roles vary significantly according to their job titles in their firms regardless of the interviewees' gender, age, years of work experience, and academic degrees. However, the interview participants' personal and professional backgrounds indicated that their work positions and job titles are related to their years of work experience and age. Even though practitioners did not perceive those variables as affecting job roles, there is a tendency among Korean practitioners for those in higher positions to be older and have more professional work experience than do those in lower positions. Therefore, in accordance with their professional experience in the communications field, their positions within their organizations, and their ages, public relations practitioners have mixed roles including three distinct primary functions. The researchers classified job titles into five categories based on the levels commonly found in Korean public relations firms: non-managerial or entry-level practitioners, first-level management, middle-level management, high-level management, and finally senior executives including CEOs, vice presidents, and directors who govern a firm's business broadly.

Public relations practitioners' perceptions of their jobs, based on the role typology established in this study, in accordance with current position, and peripheral professional experience and age are as follows:

The findings in this study demonstrate that the roles of public relations practitioners in global public relations firms in Korea involve obviously strategic counselor/manager functions such as setting goals, providing leadership for their clients, and planning and managing the implementation of communications programs on behalf of their organizations. However, those practitioners with greater professional work experience and higher positions, excluding senior executives, are more involved with strategy-oriented counselor/manager functions. Senior executives are more involved with the business manager role than with the strategy-oriented counselor/manager role. Korean public relations practitioners, regardless of their work experience or position, consider the strategic counselor/manager role as the most ideal, one which only public relations practitioners can serve. They take strong pride in this capacity and expect their activities as public relations practitioners to focus more on this role. This is encouraging considering Korea's short public relations history.

The results in this study found that, save for senior executives, all public relations practitioners function as non-strategic technicians. Notably, the youngest-those with the least professional work experience and the least responsible positions-indicated that their job roles involved relatively more non-strategic technician activity, and they showed a stronger rejection of the non-strategic technician role than did practitioners in other positions. All practitioners, including senior executives, have strong antipathy toward these non-strategic technician activities. They perceive that technician activities do not involve strategies, thus a non-strategic technician role is not proper for practitioners and should be avoided. Practitioners in this study consider the technician role to be characterized by "servant-like assistant" functions which anybody can fulfill. Such attitudes stand in contrast to their perceptions of the strategic counselor/manager role which they defined as an essential and specialized role appropriate only for practitioners.

On the other hand, only higher position practitioners, senior executives, and high-level managers perceive themselves as business managers for their own firms. However, the findings indicate all of the interviewees are actually involved in business management role. Of the interviewees, those with the greatest professional work experience and more responsible positions, especially senior executives, functioned more commonly in business roles within the practitioners' own firms. On the other hand, entry-level practitioners with the least work experience had limited business management responsibility. Entry-level practitioners' business management activities usually do not include direct responsibility as their involvement stems from their team membership. For a visual summary of 
practitioners' job roles, in accordance with their positions in their organizations, their work experience and their ages, refer to Figure 1.

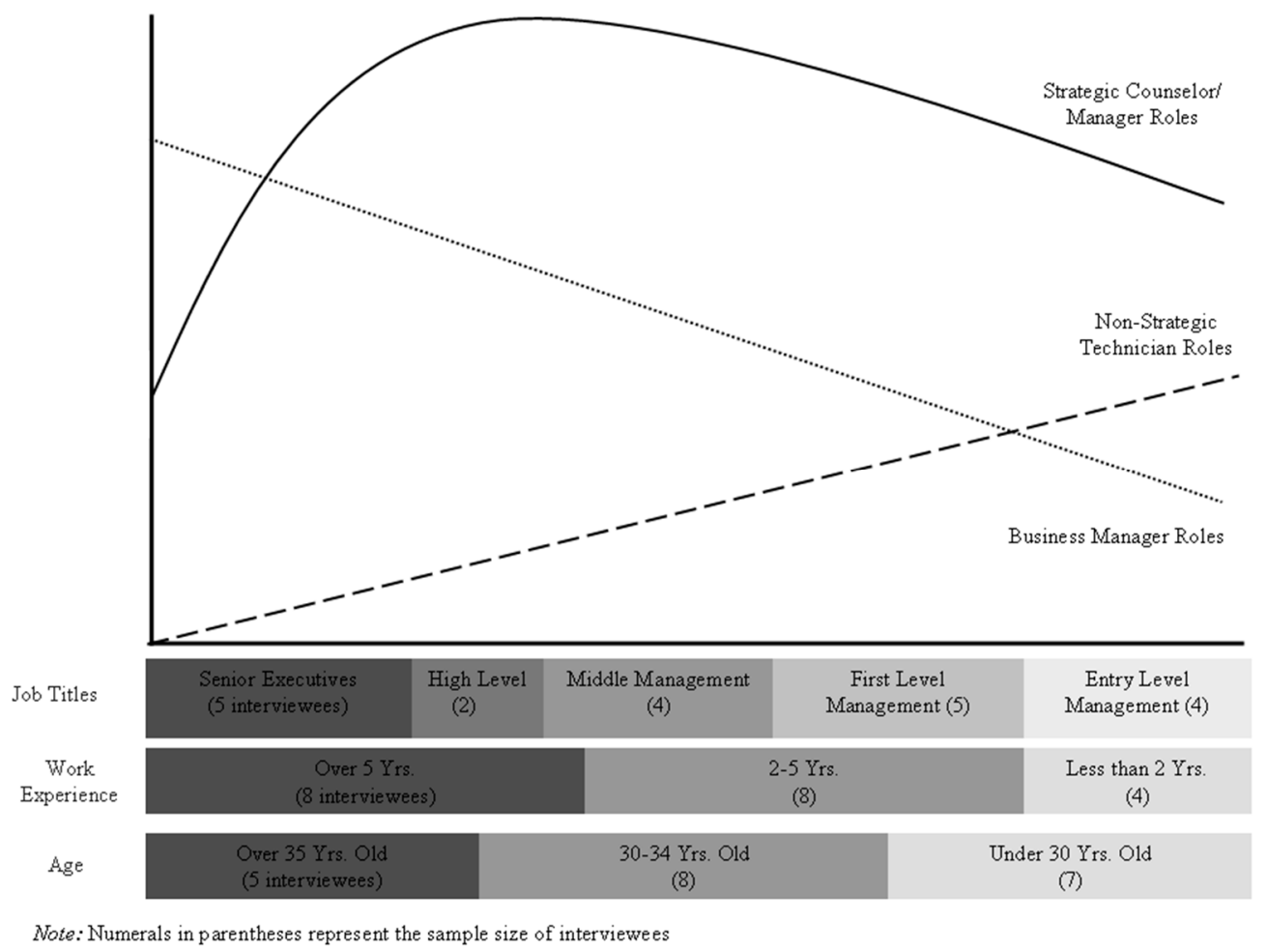

Figure 1. Practitioners' job roles, in accordance with their positions in their organizations, their work experience and their ages.

\subsection{Elements Affecting the Job Roles of Korean Practitioners in Global Public Relations Firms}

Nine elements were explored during the interviews as possible contributors to the job roles of practitioners who work in global public relations firms in Korea. Among the emergent elements, only two of which were uncovered in prior research discussion also appeared in this research, suggesting that those elements are consistently related to practitioners' interpretations of their job roles. These two influential elements are public relations practitioners' positions and their academic qualifications on their job titles. Previous research reported that senior practitioners tend to be professionally accredited and have greater supervisory responsibility, and more master's degree holders are found among the accredited than among the non-accredited [28]. Other new elements that emerged in this study included: the impact of media environmental specificity in society, and how much credibility it enjoys with the public; clients' understanding of public relations and its practitioners; control exerted by practitioners' own firms' and headquarters' policies or rules; adherence to business contracts with clients; the influence of cultural characteristics in the local branch operations headquartered in a different country or culture; and the general public's low or inaccurate perception of public relations as a non-profession.

Most importantly, Korea's unique cultural elements may be understood as both important and powerful. These elements, which involve local specific characteristics, environment, and situations including media environmental specificity and general public perceptions of public relations, emerged as important elements which practitioners perceive as affecting their roles. These culturally-oriented elements suggested, as evident during the interviews, that Korean practitioners' job roles are deeply related to Korean culture. In Hofstede's [41,42] terms, these characteristics can be viewed as: collectivist, feminine, marked by high power distance, a tendency toward strong uncertainty avoidance, and a long-term orientation. These results suggest that public relations practitioners working in global 
public relations firms in Korea regard their job roles to be affected by cultural or societal specificity even though their firms have strong corporate cultures and procedures that guide their overall operations worldwide.

\subsubsection{Element 1: Cultural Characteristics}

Interviewees gave many examples that highlighted the importance of cultural characteristics. Interviewees mentioned a relationship-oriented culture as distinctly Korean: this can be understood as a hierarchical culture of age and position based on Confucianism, collectivism, and Jeong, an emotion unique to Koreans. Jeong is a sense of oneness with others, an emotional dependence that has built up over a long time, and creates the perception of a pseudo-family encompassing others [43]. Several practitioners believe that relationship-oriented Korean culture specially affects practitioners' job roles, influencing what they have to do to build Korean-style relationships with their clients or public:

"In particular, providing clients or journalists with entertainment or gifts is a general business practice that is widely accepted in the Korean market. It represents relationship-oriented Korean culture. To build emotional intimate relationship with media or clients, practitioners have to provide entertainment and spend more time with them even after work time. You know Korean culture... it is not an overstatement that Koreans work better or more efficiently if there is an emotional bond. We feel a stronger bond when we find any connection ... school ties, geographical ties and so on ... with the business partner. For example, once I build a strong relationship with media personnel, the media personnel might help me when I ask for a positive press response regarding my clients' issues because of Jeong. Of course, I should prepare some interesting news, too. Anyhow, one of the Korean practitioners' jobs could be building personal relationships with clients or journalists, so to achieve that goal, practitioners serve them."

A high-level female manager shared a similar opinion that a relationship-oriented culture is based on this emotional bond which seems to be prevalent at work in Korea. She said that she unintentionally tries to do more or better work for longer-term relationship clients and hardly ever rejects such clients' requests (even those related to technical aspects). She explained this as a result of the stronger trust and emotional bond with long-term relationship clients.

Some interviewees mentioned the hierarchical culture of age as an especially Korean characteristic which can affect their job roles. A 29 year-old male, a middle manager, explained that in working with clients much older than himself, he was often treated like a younger brother or an "assistant". They showed him little respect as a younger person, instead expecting him to respect their opinions despite his having more than four years' work experience in public relations. He emphasized his point by sharing an observation:

"Young practitioners sometimes are limited in their work on government projects because young age is not trusted by old government officials. Young practitioners can't be assigned responsible jobs but only assistant roles."

\subsubsection{Element 2: Media Environmental Specificity}

Another critical element is media environmental specificity. It is related to how much power media have or what position media hold in a given society. Most of the interviewees, spread over all the levels of positions, mentioned that the media have unbelievable power in Korea and that the media are deeply involved with their job roles. One interviewee alluded to a pecking order with the media on top, followed by the clients, and the public relations firms on bottom. He described this as a uniquely Korean situation:

"Media journalists, especially the journalists who are related to my clients' industry and who request some information from me are like bosses over my work. Or, I would say they are king! 
They govern my roles at work. They have big power and we, PR practitioners are affected by them. In general people trust the information media release, so I should listen to media journalists' every word as well as to their requests. Then I can have good results or achievement in my public relations practice. This is the reality!"

Another practitioner interpreted the Korean media environment as deeply involved with Korean special cultural characteristics by mentioning "media-centrism":

"Korea's media-centered culture is related to Korea's unique cultural specificity. Because of media's special power in Korea, family ties, school ties, and geographical origin ties, which public relations practitioners have, are usually involved with media to control media. And monetary transactions and entertainment for media happen in public relations business."

\subsubsection{Element 3: The General Public's Perception of Public Relations as Unprofessional}

All of the interviewees said they believed that broad societal perceptions of public relations affected their job roles and that the public perception was related to the professionalism of their job roles. They also believed their roles contribute to the enhancement of public relations professionalism. However, they think the general public's lack of understanding of public relations causes them to be viewed as unprofessional and it reduces them to performing the technical role of assistants or agents:

"I myself consider public relations to be a professional field, but most people do not share my opinion. I think the public's general perception of public relations leads to my clients' perceptions that public relations practitioners are secondary assistants. Clients' perceptions affect my job role as a technician ... which involves trivial errands, making simple invitation cards, or promoting specific events while having no power to make decisions."

One of the interviewees expressed an interesting opinion regarding the public's perception of public relations:

"Those who don't know about public relations might perceive that practitioners' jobs are cool because they think we do something creative. Those who know a little about public relations perceive practitioners' job as tough because practitioners have to be the legs and arms of their clients. Those clients perceive practitioners as "cheap agent for them" and the media think practitioners are bothersome but necessary beings. This is a practitioners' reality. The public's different perceptions decide a practitioners' work."

Another interviewee indicated an especially strong rejection of the general perception of public relations:

"While a medical doctor, lawyer, or pharmacist, as it is called "professional" by social agreement, public relations practitioners are not perceived that way by the public. Still ... many people don't know what public relations is and what public relations practitioners do. Even my parents don't know what it is and asked me ... like ... so what do you do at work? (laugh) ... it is a pity."

In response to the general public's perception of public relations as being unprofessional, interviewees offered many suggestions for the enhancement of public relations professionalism: higher salaries and fringe benefits, professional certification like that of doctors or lawyers, higher levels of education, training, business mind-setting, communication skills, strategic thinking capability, creativity, and a professional association considered authoritative like the Korean Bar Association. There was a general suggestion that the entire Korean public relations field requires some serious attention. The Korean public needs to know what public relations practitioners do for the public. Among the suggestions for enhancing the perception of professionalism, public relations specialization was advanced by all the interviewees: 
"I believe that public relations practitioners debase themselves by providing unlimited services 'from $A$ to $Z$ ', a characteristic related to the subordinate relationship mentioned previously. Distinct definition of work areas will aid in public relations specialization."

Another significant comment from all interviewees was that professional enhancement is deeply related to ethics. They believe that each firm needs to have a strict code of ethics and ethical training regarding the firm's standards to enhance public relations professionalism.

\subsubsection{Element 4: Client Perceptions of Public Relations/Client Relationships}

The data suggest that yet another element affecting the job roles of practitioners is client perceptions of public relations and practitioners' client relationships. The interviewees explained their perceptions that clients' low understanding of public relations, limited experience working with practitioners, or improper relationship between clients and practitioners all constituted negative influences. It is interesting that all of the interviewees depicted their relationships with clients using expressions such as "subordinate relationship", "unfair relationship", or "assistant relationship":

"I think many clients perceive public relations practitioners as their agents, lower class, or subordinate personnel who assist them in their jobs ... jobs which they originally thought they could handle alone ... but which they no longer can because they don't have time to do everything. Because they think we are their assistants or secretaries, they ask practitioners to be their arms and legs. As clients make requests, I have no choice but to provide all kinds of services including some which are not part of my main roles. So ... I think the relationship with clients and how they perceive public relations or practitioners' roles determine my roles as a public relations practitioner."

\subsubsection{Element 5: Practitioners' Own Firms' Principles and Rules}

One of the critical elements that always affects practitioners' roles is their own firms' principles and rules. Practitioners stated that they belong to an organization, so they function as their firms' designees, and if the organization does not allow them to do something, they have to follow that regulation:

"My firm has some special rules and policies. My firm's policies have more influence than anything else has on my role as a practitioner. Sometimes, my clients ask me to do some work for them but I have to reject it based on my firm's rules ... well ... for example, sometimes, I have a request from my clients to drink alcohol or enjoy entertainment with media people after my regular work time, but my firm has a rule that requires me to reject this kind of request from clients. Thank God!"

\subsubsection{Element 6: Headquarters' Principles and Rules}

Similarly, headquarters' principles and rules were commented upon by some interviewees. They noted that headquarters' influence on their roles was related with the influence of practitioners' local organizations. A male senior executive shared the following interpretation:

"As practitioners, who work in an international PR firm which has headquarters in America, we are obliged to comply with American concepts in determining what kind of job roles are acceptable and what are not. American standards, which are often regarded as global standards, usually do not allow us to follow Korean business practices. Therefore when we tried to establish relationships with stakeholders in the Korean style, it was rejected by our headquarters ... so ... we have to take much more time to build relationships with Korean stakeholders."

\subsubsection{Element 7: Business Contracts with Clients}

Several interviewees reported that business contracts with clients or clients' business guidance are a critical element contributing to their job roles:

"My firm has contracts with government and publicly held organizations. I do my work based on those contracts. It is a three-month project for research and some strategies regarding government 
issues. So I am like a researcher.... I don't actually practice what I have suggested for the project.

I also don't do menial technical work because I just do consultant roles or researcher roles."

Interviewees stated that the contract decides practitioners' work sphere when there is work conflict with the client.

\subsubsection{Element 8: Practitioners' Positions/Job Titles}

The data suggest that job roles differ in accordance with practitioners' positions in their organizations. It shows that higher positioned practitioners have more responsibility and wider managerial roles, including managing business and lower-level employees. Interviewees insisted that job titles represent what they have to do. Some of them felt strongly that work position by hierarchy affects what they have to do or not do in their work:

“... my boss' opinion or decision affects what I have to do. I should have my boss' confirmation for all my documentation before I send it to my clients. If my boss does not agree with my work, I should change my work... I think it is partly related to Korean culture of hierarchy."

\subsubsection{Element 9: Practitioners' Academic Qualifications}

Another element affecting the job roles of practitioners in this study was practitioners' own knowledge or academic degrees. The interviewees exemplified how practitioners' academic degrees or their knowledge on issues affect their job roles; their firms assign practitioners who have master's degrees in communication or public relations to consulting projects which mainly involve research, not practice. On the other hand, practitioners who have only bachelor's degrees mostly are not involved with that kind of consulting project. Even though they are involved, it is rare or they are not responsible for the project. Practitioners stated that most public relations firms in Korea recruit master's degree holders as practitioners and that clients want practitioners with advanced degrees. In fact, 13 of the 20 interview participants in this study have master's degrees and one senior executive is currently working on his doctorate. One interview exemplified how practitioners' academic degrees or their knowledge on issues affect their job roles:

"My firm assigns practitioners who have master's degrees in communication or public relations to consulting projects which mainly involve research, not practice. On the other hand, practitioners who have only bachelor's degrees mostly are not involved with that kind of consulting project. Well, even though they are involved, it is rare or they are not responsible for the project. A consulting project requires professional research ability which can be acquired at the masters' level in a communication major. Practically, if they don't have specific research or analysis ability, it is hard to achieve certain roles."

\section{Discussion and Conclusions}

This study advances a job role typology comprised of three distinct roles among Korean public relations practitioners in global public relations firms: strategic counselor/manager role, non-strategic technician role, and business manager role for practitioners' own firms. This newly defined and conceptualized framework explains what it is that public relations practitioners actually do. The strategic counselor/manager role in this study differs from managerial roles that were previously defined because this newly identified strategic counselor/manager role includes every function related to public relations strategies. Technician roles presented in previous research were re-identified here as non-strategic roles; the non-strategic role does not involve any strategic work, making the individuals in these positions somewhat interchangeable. Thus, press release writing and editing, and media contacts, which were categorized as part of the technician role in prior research, are re-identified as strategic counselor/manager role if they involve strategizing. By applying public relations strategies to previous technician roles, practitioners who work in global public relations firms seem to broaden 
their scope of professionalism. This study also newly explored the business manager role as one of the primary and unique roles public relations practitioners may serve in global firms, a role not found in corporate in-house environments. Further research is needed, however, to clarify whether this business role of practitioners is unique to Korean public relations firms, or universally applicable to public relations firms elsewhere. The findings of this study support prior research [27] that position at work, work experiences, and age can affect practitioners' roles. However, the finding that gender differences do not affect the pattern of practitioner roles contradicts the previous research (e.g., [22-30]. This may be attributed to the situation in Korean public relations firms in which females represent an overwhelming majority [38].

This exploratory study offers valuable knowledge that there are various elements contributing to the job roles of practitioners who work in global public relations firms in Korea. Especially, Korea's unique cultural elements were defined as both important and powerful. Those elements found in this research which involved human relationships, including media relationships, client relationships, and employee relationships in practitioners' firms, based on their positions in their organizations, and general public relationships, are deeply influenced by the Confucian mind-set. That is, Korean cultural values, which can be characterized as hierarchical, collectivistic, and long-term relationship-oriented, are essentially Confucian. Therefore, even though Korean practitioners are part of global public relations firms and perceive their firms' headquarters' rules as elements affecting their job roles, Confucian-based human relationship values seem to have a greater influence on practitioners' perceptions of their roles. Significantly, media environment specificity in Korea is one of the strongest contributors to Korean practitioners' perceptions of their job roles. The Korean media environment reflects a mixed form of the characteristics of Confucianism and Korean media specificity. In Korean society, there is a plethora of media which have tremendous power and influence on the public. Thus Korean public relations practitioners are sensitive to media response, and their relationship to media could be termed submissive. Once they establish personal relationships with media personnel, based on loyalty and faith, such relationships affect practitioners' job roles. The human relationship-oriented elements which contribute to Korean practitioners' perceptions of their job roles form an uniquely Korean style of public relations professionalism, similar to what has been named "Confucianism-oriented professionalism" [44]. These results suggest that practitioners working in global public relations firms regard their job roles to be affected by cultural or societal specificity even though their firms have strong corporate cultures and procedures that guide their overall operations worldwide.

Those elements found in this research demonstrate the same compound nature affecting practitioners' perceptions of their ethics explored by Jeong [44]. In other words, elements that affect practitioners' ethical decision-making also emerged as influential on practitioners' roles. This is noteworthy as it supports the assumption that the job roles and ethics that are both so deeply involved with professionalism are, in fact, interconnected. The interview data presented here also supported these results. All public relations practitioners in this study perceive a strong relationship between professionalism and ethics, and view ethics as an essential skill set if one is to be a professional in the public relations field. Practitioners can create a synergistic effect toward enhancing professionalism by acknowledging this relationship. Finally, analysis of the elements common to both practitioners' roles and their ethical decision-making could be a productive step toward enhancing public relations professionalism. Practitioners can create a synergistic effect toward enhancing professionalism by acknowledging this relationship. Finally, analysis of the elements common to both practitioners' roles and their ethical decision-making could be a productive step toward enhancing public relations professionalism.

On a practical level, this research suggests that job roles and professionalism influence each other and are mutually complementary. This finding not only suggests that practitioners' job roles are influenced by the elements found in this study, but also provides critical clues to the process of enhancing professionalism. In this sense, this research suggests that practitioners should acknowledge 
elements that affect their job roles. Practitioners can enhance professionalism and even entrepreneurial sustainability by augmenting positive elements affecting their roles and by lessening the impact of negative elements. Among many suggestions of the interviewees regarding the enhancement of professionalism, public relations specialization was seen as a significant contributor. As a result, public relations practitioners will be better able to make optimal decisions regarding their client organizations' adopted strategy.

Further research should employ both qualitative and quantitative methods to test these findings and the elements identified in this study as contributors to practitioners' job roles. Other forms of qualitative research, including focus group interviews of practitioners considering demographic segments, may be useful in elaborating on the job role typology advanced in this study, and confirming whether practitioners agree or disagree that the elements found in this study do indeed affect their job roles. Additional studies may also use comparative research between countries, and consider other forms of public relations work environments including corporate in-house and general public relations firms. Such comparative research could help to test the findings of this study and lead to further meaningful discoveries.

Acknowledgments: This paper was improved by constructive reviews and comments at the conference and during the reviewing process. We appreciate anonymous reviewers and editors for their thoughtful comments.

Author Contributions: All authors contributed equally to collecting and analyzing the data as well as designing and writing this article. Further, they have all read and approved the final manuscript.

Conflicts of Interest: The authors declare no conflict of interest.

\section{Appendix A}

Table A1. Examples of Interview Questions.

- Describe your daily life at work. Then, explain what aspects of it satisfy or dissatisfy you. [This question speaks to the real role of public relations practitioners and their satisfaction with their job roles.]

- Describe your roles related to your clients. Then, explain what aspects of them satisfy or dissatisfy you. [This question helps to define public relations practitioners' roles in the public relations field and the satisfaction inherent in them.]

- What are your expectations of your work? [This question helps understand public relations practitioners' perception of job roles.]

- Describe the elements which influence your job roles. How much do such elements contribute to your work? [This question helps define the elements that influence job roles.]

- What do you think of the status of public relations practitioners in Korea? Do you think they are considered to be professionals in Korean society? [This question probes public relations practitioners' perceptions of their jobs and their professionalism as well as their relationship to Korean society.]

- In your opinion what efforts are needed to foster professionalism among Korean public relations practitioners? [This question speaks to the public relations practitioners' perception on professionalism.]

- How do you regard your job role, as a public relations practitioner in a global company, compared to those of other public relations practitioners who work in Korean domestic companies? Explain why. [This question speaks to the general perceptions of public relations practitioners of their job roles as well as to elements, both cultural and individual, which influence job roles.]

- Have you experienced a situation where the expectations of headquarters' personnel differed significantly from those of branch staff or your firm's expectations? If so, what was the conflict? How did you manage it? [This question speaks directly to the influence of different cultures on job roles and on conflict management.]

- What unique aspects of Korean culture influence your job roles? [This question addresses the influence of culture on job roles.]

- What elements do you think are needed to enhance professionalism? [This question helps define public relations practitioners' perceptions of professionalism as well as their relationship to their profession.] 


\section{References}

1. Broom, G.M.; Smith, G.D. Testing the practitioner's impact on clients. Public Relat. Rev. 1979, 5, 47-59. [CrossRef]

2. DeSanto, B.; Moss, D. Rediscovering what PR managers do: Rethinking the measurement of managerial behavior in the public relations context. J. Commun. Manag. 2004, 9, 179-196. [CrossRef]

3. DeSanto, B.; Moss, D.; Newman, A. Building an understanding of the main elements of management in the communication/public relations context: A study of U.S. practitioners' practices. J. Mass Commun. Q. 2007, 84, 439-454. [CrossRef]

4. Dozier, D.M. Program evaluation and the roles of practitioners. Public Relat. Rev. 1984, 10, 13-21. [CrossRef]

5. Dozier, D.M.; Broom, G.M. Evolution of the manager role in public relations practice. J. Public Relat. Rev. 1995, 7, 3-26. [CrossRef]

6. Lauren, M.M. Public relations practitioner role enactment in issues management. J. Q. 1994, 71, 356-369.

7. Lee, N.M.; Sha, B.-L.; Dozier, D.M.; Sargent, P. The role of new public relations practitioners as social media experts. Public Relat. Rev. 2015, 41, 411-413. [CrossRef]

8. Neil, M.S.; Moody, M. Who is responsible for what? Examining strategic roles in social media management. Public Relat. Rev. 2015, 41, 109-118. [CrossRef]

9. Mellado, C.; Barría, S. Development of professional roles in the practice of public relations in Chile. Public Relat. Rev. 2012, 38, 446-453. [CrossRef]

10. Roux, T. The description of South African corporate communication practitioners that contribute to organizational performance. Public Relat. Rev. 2014, 40, 193-215. [CrossRef]

11. Yeo, S.L.; Sriramesh, K. Adding value to organizations: An examination of the role of senior public relations practitioners in Singapore. Public Relat. Rev. 2009, 35, 422-425. [CrossRef]

12. Molleda, J.C.; Moreno, A.; Athaydes, A.; Suarez, A.M. Macroencuesta latinoamericana de comunicacion y relaciones publicas. Organicom 2010, 7, 119-141.

13. Molleda, J.C.; Ferguson, M.A. Public relations roles in Brazil: Hierarchy eclipses gender differences. J. Public Relat. Rev. 2004, 16, 327-351. [CrossRef]

14. Gonzalez, H.; Akel, D. Elections and earth matters: Public relations in Costa Rica. In International Public Relations. A Comparative Analysis; Culbertson, H.M., Chen, N., Eds.; Lawrence Erlbaum Associates: Mahwah, NJ, USA, 1996; pp. 257-272.

15. Jeong, J.Y. Enhancing organizational survivability in a crisis: Perceived organizational crisis responsibility, stance, and strategy. Sustainability 2015, 7, 11532-11545. [CrossRef]

16. Broom, G.M.; Sha, B.-L. Cutlip and Center's Effective Public Relations, 11th ed.; Pearson: Boston, MA, USA, 2012.

17. Berkowitz, D.; Hristodoulakis, I. Practitioner roles, public relations education, and professional socialization: An exploratory study. J. Public Relat. Rev. 1999, 11, 91-103. [CrossRef]

18. Lauren, M.M.; Dozier, D.M. The missing link: The public relations manager role as a mediator of organizational environments and power consequences for the function. J. Public Relat. Rev. 1992, 4, 205-220.

19. Leichty, G.; Springston, J. Elaborating public relations roles. J. Mass Commun. Q. 1996, 73, 467-477. [CrossRef]

20. Moss, D.; Warnaby, G.; Newman, A.J. Public relations practitioner role enactment at the senior management level within U.K. companies. J. Public Relat. Rev. 2000, 12, 227-307. [CrossRef]

21. Moss, D.; Newman, A.; DeSanto, B. What do communication managers do? Defining and refining the core elements of management in a public relations/corporate communication context. J. Mass Commun. Q. 2005, 82, 873-890. [CrossRef]

22. Toth, E.L.; Serini, S.A.; Wright, D.K.; Emig, A.G. Trends in public relations roles: 1990-1995. Public Relat. Rev. 1998, 24, 145-163. [CrossRef]

23. Broom, G.M.; Dozier, D.M. Advancement for public relations role models. Public Relat. Rev. 1986, 12, 37-56. [CrossRef]

24. Choi, Y.; Hon, L.C. The influence of gender composition in powerful positions on public relations practitioners' gender-related perceptions. J. Public Relat. Rev. 2002, 14, 229-263. [CrossRef]

25. Cline, C.G.; Toth, E.L.; Turk, J.V.; Walters, L.M.; Johnson, N.; Smith, H. The Velvet Ghetto: The Impact of the Increasing Percentage of Women in Public Relations and Business Communication; International Association of Business Communicators Research Foundation: San Francisco, CA, USA, 1986. 
26. Creedon, P.J. Public relations and "women's work": Towards a feminist analysis of public relations roles. In Public Relations Research Annual; Grunig, L.A., Grunig, J.E., Eds.; Lawrence Erlbaum Associates: Hillsdale, NJ, USA, 1991; pp. 67-84.

27. Dozier, D.M.; Grunig, L.A.; Grunig, J.E. Manager's Guide to Excellence in Public Relations and Communication Management; Lawrence Erlbaum Associates: Mahwah, NJ, USA, 1995.

28. International Association of Business Communicators. Available online: http:/ findarticles.com/p/articles / mi_m4422/is_5_19/ai_91213364/(accessed on 30 July 2017).

29. Toth, E.L.; Cline, C.G. Beyond the Velvet Ghetto; International Association of Business Communicators Research Foundation: San Francisco, CA, USA, 1993.

30. Toth, E.L.; Grunig, L.A. The missing story of women in public relations. J. Public Relat. Rev. 1993, 5, $153-175$. [CrossRef]

31. Vanc, A.; White, C. Cultural perceptions of public relations gender roles in Romania. Public Relat. Rev. 2011, 37, 103-105. [CrossRef]

32. Han, J. A typological study on the PR practitioners' perception toward their job roles and functions. Korean J. Mass Commun. Q. 2002, 46, 112-249.

33. Kim, I.S. AQ study of practitioner perceptions about public relations practitioner's role and expertise for U.S.-Based multinational corporations in Korea. Presented at the Thirteenth Annual Conference of the International Society for the Scientific Study of Subjectivity, Syracuse University, Syracuse, NY, USA, October 23-25 1997.

34. Korean Businessman Association. The Guideline for Public Relations Practitioners: How Businessman Can Handle Mass Media? Korean Businessman Association: Seoul, Korea, 1999.

35. Kim, Y.; Hon, L. Craft and professional models of public relations and their relation to job satisfaction among Korean public relations practitioners. J. Public Relat. Rev. 1998, 10, 155-175. [CrossRef]

36. Marshall, C.; Rossman, G.B. Designing Qualitative Research, 6th ed.; Sage Publications: Thousand Oaks, SA, USA, 2016.

37. The Korea PR Consultancy Association. Available online: http://www.kprca.or.kr/members/members1.asp (accessed on 30 July 2017).

38. Edelman Korea. Available online: http://www.edelman.co.kr/web/insight/insights_view.php?class= \&uid=15 (accessed on 30 July 2017).

39. Lindlof, T.R. Qualitative Communication Research Methods, 2nd ed.; Sage Publications: Thousand Oaks, CA, USA, 2011.

40. Eisenhardt, K.M. Building theories from case study research. Acad. Manag. Rev. 1989, 144, 548-549.

41. Hofstede, G. Cultures Consequences: International Differences in Work-Related Values; Sage Publications: Newbury Park, CA, USA, 1980.

42. Hofstede, G. Cultures and Organizations: Software of the Mind; McGraw Hill: London, UK, 1991.

43. Han, J.; Jeong, J.Y. A study on the influence of the organization-public relationships on the public's perception during an organization's crisis situations. Korean J. Journal. Comm. Stud. 2002, 46, 588-633.

44. Jeong, J.Y. PR practitioner's perceptions of their ethics in Korean global PR. Public Relat. Rev. 2011, 37, 99-102. [CrossRef]

(C) 2017 by the authors. Licensee MDPI, Basel, Switzerland. This article is an open access article distributed under the terms and conditions of the Creative Commons Attribution (CC BY) license (http://creativecommons.org/licenses/by/4.0/). 